\title{
Parental Physical Activity: Exploring the Role of Social Support
}

Kyra Hamilton, BNursing, BPsych(Hons); Katherine M. White, BA(Hons), PhD

Objectives: To explore the influence of social support on parental physical activity (PA). Methods: Forty parents $(21$ mothers, 19 fathers) participated in semistructured individual or group interviews. Data were analyzed using thematic content analysis. Results: Instrumental (eg, providing child care, taking over chores), emotional (eg, encouragement, companionship), and informational support (eg, ideas and advice) as well as reciprocal support (eg, giving as well as receiving support) and autonomy support (eg, respecting one's choices) are important for parents' PA behavior. However, having support for being active is not straightforward in that many parents discussed issues that inhibited the facilitative nature of social support for PA performance (eg, guilt in getting help). Conclusions: Results highlight the complex nature of social support in facilitating parental PA.

Key words: physical activity, exercise, social support, parent, qualitative

Am J Health Behav. 2010;34(5):573-584
I nactivity is a global concern concern, and the Australian population, for whom 1 physical inactivity is responsible for $6.6 \%$ of the total burden of disease and injury, is no exception. ${ }^{1}$ Despite regular moderate physical activity (PA) being a key component to a healthy lifestyle, ${ }^{2}$ approximately $70 \%$ of Australians aged 15 years and over are classified as sedentary or having low exercise levels. ${ }^{3}$ Although the lack of PA is of concern for the entire Australian population, research indicates that certain population groups are less likely to be active, including parents of dependent children who, only recently,

Kyra Hamilton; Katherine M. White, Associate Professor, School of Psychology and Counselling, Queensland University of Technology, Victoria Park Road, Queensland, Australia.

Address correspondence to Ms Hamilton, School of Psychology and Counselling, Queensland University of Technology, Victoria Park Road, Queensland, 4059, Australia. E-mail: k2.hamilton@qut.edu.au have been found to be less active than nonparents. ${ }^{4}$ In particular, research suggests that the presence of a young child in the household (ie, younger than 5 years of age) has a greater negative influence on parental PA than having older children present. ${ }^{5}$ Despite the trend in decreasing PA with the presence of children, however, there is currently little research exploring the underlying issues that may influence parental PA. This lack of investigation is cause for concern for a number of reasons. First, engaging in regular PA has numerous health benefits both long and short term ${ }^{2}$ as well as positive effects on parenting practices, such as increasing confidence in performing the parenting role. ${ }^{6}$ Second, research suggests a positive relationship between parent and child PA. ${ }^{7,8}$ Finally, activity habits are often difficult to reestablish once broken. ${ }^{9}$

Social influences are especially salient for parents of young children, and the social contexts in which parents operate may influence and shape their deci- 
sion making about PA. Social support is one social influence that is found to have strong positive associations with PA behavior with the results being evidenced across both cross-sectional and prospective research ${ }^{10,11}$ and intervention studies. ${ }^{12}$ Social support is often conceptualized as "aid and assistance exchanged through social relationships and interpersonal transactions."13, p.187 Expanding on the social support definition, House ${ }^{14}$ advocated that social support is the functional content of a relationship that can be categorized into 4 major types that may be experienced positively or negatively: (1) emotional support (expressions of love and trust), (2) instrumental support (tangible aid and service), (3) informational support (advice and information), and (4) appraisal support (constructive feedback and affirmation). Another function of social support is related to reciprocity, the giving and receiving of resources between provider and recipient. ${ }^{15}$ Although the notion of reciprocity fits with the overall definition of social support (ie, the exchange of support), its function is often overlooked in the literature despite evidence to suggest that reciprocity correlates with other social support constructs. ${ }^{16}$ Apart from various types of support (such as emotional and instrumental types), a number of sources of support are also found to influence behavior, in particular, the support from family members and friends. ${ }^{17}$ Thus, it has been argued that no single definition of social support will be adequate to capture the multiple dimensions inherent within the construct. ${ }^{13,18,19}$

Although the importance of social support for PA performance has been widely accepted, ${ }^{10}$ few studies have examined the various social support dimensions in relation to parental PA. Thus, currently there is little understanding of the effects of the different sources (eg, family, friends) and types (eg, child care, encouragement, ideas) of support on parents' PA or the mechanisms by which the direction of social support might influence such behavior. Additionally, despite the importance of social support for activity performance in general, discrepancies in the literature exist in which some studies have found social support to have limited predictive ability on people's PA intentions and behavior. ${ }^{20}$ Furthermore, the effect of social support on PA is relatively small compared to the effect of other so- cial-cognitive processes, such as attitudes. ${ }^{11}$ The equivocal findings might, in part, be due to how specific cohorts of the population perceive social support as influencing their activity performance. For example, ethnicity may influence perceptions of social support to performing $\mathrm{PA}^{21,22}$ as might gender in which social support is found to be more influential for females' rather than for males' PA-related behavior. ${ }^{23,24}$ The discrepancy in the findings may also be due to the lack of emphasis on gaining a rich understanding of how the interrelationships among the supportive dimensions (ie, the influence of the different people providing the support and the influence of the various types of support these people provide) influence one's activity behavior. Thus, to better understand the importance of social support on people's PA behavior and, therefore, provide the most beneficial recommendations for intervention programs, these interrelationships, as they relate to specific population groups, must be elucidated clearly. Qualitative methodology is best equipped for gaining a richer understanding of such relationships. ${ }^{25}$

A small number of qualitative studies that have explored the barriers women face with the presence of children in relation to PA have illustrated the importance of supportive social environments. ${ }^{22,26-28}$ In particular, researchers have found that family and friends are important sources of support and provide important types of support for increasing PA including child care and motivation. ${ }^{22,27}$ The existing research, however, is scarce, and further studies are needed to identify what specific types and sources of support facilitate parental activity and how they might affect parental PA behavior. This analysis will also help to elicit the most appropriate taxonomy of social support for understanding parental PA and, as such, help to gain insight into whether parents' perceptions of support for activity fit established classifications of social support. This understanding is important given that there is still some debate surrounding the conceptualization of social support. ${ }^{18,19}$ Furthermore, the current literature highlights the voices of mothers, and no study has tried explicitly to explore and compare the social support perceptions of both mothers and fathers, which is important given that both females ${ }^{29,30}$ and 


\section{Table 1 \\ Demographic Characteristics of the Full Sample $(N=40)$}

\begin{tabular}{|c|c|c|}
\hline Characteristics & Mother $(n=21)$ & Father $(n=19)$ \\
\hline \multicolumn{3}{|l|}{ Age, years } \\
\hline Mean (Range) & $35(23-42)$ & $37(26-49)$ \\
\hline \multicolumn{3}{|l|}{ Level of Education (n) } \\
\hline No high school diploma & 2 & 4 \\
\hline High school diploma & 3 & 5 \\
\hline Diploma/trade certificate & 3 & 3 \\
\hline University degree & 11 & 5 \\
\hline University graduate degree & 2 & 2 \\
\hline \multicolumn{3}{|l|}{ Work Status (n) } \\
\hline Full-time & 3 & 17 \\
\hline Part-time & 6 & 0 \\
\hline Casual & 3 & 1 \\
\hline Unemployed & 1 & 0 \\
\hline Student & 1 & 0 \\
\hline Home duties & 7 & 1 \\
\hline \multicolumn{3}{|l|}{ Marital Status (n) } \\
\hline Single & 2 & 1 \\
\hline Married & 17 & 15 \\
\hline Common-law & 1 & 1 \\
\hline Separated & 1 & 2 \\
\hline \multicolumn{3}{|l|}{ Number of Children (n) } \\
\hline 1 child & 12 & 4 \\
\hline 2 children & 7 & 7 \\
\hline 3 children & 0 & 3 \\
\hline 4 children & 2 & 5 \\
\hline \multicolumn{3}{|l|}{ Age of Children, Years (n) } \\
\hline Median & 2 & 3 \\
\hline Mode & 1 & 2 \\
\hline Range & 8 months -13 years & 7 months -21 years \\
\hline \multicolumn{3}{|l|}{ Level of Physical Activity } \\
\hline Never active & 1 & 0 \\
\hline Rarely active & 2 & 3 \\
\hline Sometimes active & 10 & 7 \\
\hline Regularly active & 8 & 9 \\
\hline
\end{tabular}

males'31 PA declines with the presence of children.

The current study aimed to explore the influence of social support on parental PA. Using qualitative methodology as well as adopting an a priori analysis (ie, identifying themes based on established theory ${ }^{25}$ ), the study sought to gain insight into the specific social support dimensions that influence both mothers' and fathers' regular PA performance. Furthermore, the study sought to determine whether current constructs of social support are useful to draw on when understanding parental PA-related behavior.

\section{METHODS}

The research was carried out between September 2008 and March 2009 in South East Queensland, Australia. The study was approved ethical clearance by the university human research ethics committee (reference number 0800000516).

\section{Participants}

A purposeful sampling method ${ }^{32}$ was used to recruit mothers and fathers of children aged less than 5 years. Participants were excluded if they were pregnant and/or had a medical condition that prevented performing PA at the recom- 
mended levels (ie, based on the current Australian guidelines ${ }^{2}$ ). This study aimed to ensure that a broad range of different experiences and perceptions was identified; as such, consideration was given to the inclusion of information-rich cases that reflect the population diversity. Maximum variation sampling, ${ }^{32}$ therefore, was used to ensure respondents ranged in age, gender, number of dependents, marital status, education level, and employment status. In addition, to ensure that the sample varied somewhat on the key demographic characteristic of PA, parents were asked to indicate the level of PA they currently engaged in on a singleitem rating scale ranging from "I never engage in physical activity" to "I regularly engage in physical activity" (Table 1). All of the parents were white, independent of each other (ie, individuals were not in a couple relationship), and resided in predominantly urban areas.

Parents were recruited via snowball sampling, ${ }^{32}$ with initial participants recruited through the researchers' contacts within work and family/friend networks. Participants were then asked to recommend participation to their social networks. In addition, recruitment flyers were placed at 4 child care centers, and although they were chosen via convenience, an attempt was made to provide a representation of a range of demographic areas and population diversity. Sample size was determined by the achievement of theoretical saturation (ie, data collected until no new themes emerged ${ }^{33}$ ). All participation was voluntary, and all interviewed individuals were given a university emblem cap as a small thank you gift for participation.

\section{Design and Procedure}

The study employed a qualitative descriptive research design ${ }^{34}$ involving focus group methodology. ${ }^{35,36}$ To allow for higher involvement from participants and, therefore, gain a more in-depth understanding of social support influences on PA behavior, focus groups of approximately 4 participants per group were initially sought. ${ }^{36}$ However, smaller sized focus groups were conducted in cases where parents did not attend a scheduled group interview session. Additionally, to limit a potential sampling bias from participants who wished to participate but who could not attend a focus group session or if only one person arrived for an arranged focus group session, an individual interview (rather than a focus group) was conducted. We believe the use of multiple methods offered a way of strengthening the study design by providing a means of triangulating data obtained via the different interview methods. ${ }^{32}$ In total, the study comprised 8 focus groups and 19 interviews, with the size of group interviews ranging from 2 to 4 participants. In addition, to eliminate the potential of gender differences influencing the sharing within the group, ${ }^{35}$ homogenous groups in relation to gender were formed. Interviews, therefore, were separated into male and female groups.

To guide the interviews, a semistructured discussion/interview guide was developed. ${ }^{\text {see eg, } 37}$ The discussion guide comprised open-ended questions that were broadly informed by social support theories; ${ }^{\text {eg, } 14,16,17}$ however, the sessions were flexible to allow refinement of questions based on emerging concepts and to improve the interviewer's understanding of points raised..$^{33,35}$ First, participants were asked to give their thoughts on getting assistance from others to do regular PA. The interviewer then used questions and prompts to ensure that particular social supportive issues were explored. Specifically explored were the sources of support that help parents to be active (eg, Who are the people that would help or assist your doing regular PA?), the types of assistance that are provided to help parental PA (eg, What types of assistance would help or assist your doing regular PA? How is receiving this assistance helpful for your doing PA?), and the effect of giving as well as receiving support for performing regular PA (eg, Support for doing PA can be received as well as be given, what are your thoughts on this? Do you think this notion of giving as well as receiving support would affect your doing PA?). The interviews were held in a setting (eg, local library, workplace, home) and at a time of day convenient for the participant. The first author conducted all interviews, which averaged 1 hour in length, and all discussions were audiotaped. For the duration of the study, a reflexive journal was kept by the interviewer in which key ideas and issues expressed, comparisons and contrasts among the interviews, and possible refinement of questions were recorded. ${ }^{38,39}$ 
Hamilton \& White

\section{Data Analysis}

The focus group/interview discussions were transcribed verbatim, and participants were assigned pseudonyms. Data were analyzed using thematic content analysis ${ }^{40,41}$ and analysis started with the running of the first interview and continued concurrently with the data collection process. ${ }^{42}$ The first author coded the transcripts line by line, and the second author (who was not present during the interviews) reviewed the codes and commented on any inconsistency in coding assignments. During the coding process, any words or sentences that captured the key issues and perceptions expressed by the parents were highlighted. Highlighting the passages helped to break down the text and organize the data into categories. These categories were then transferred into tables constructed in MS Word. The tables provided a visual representation of the data that enhanced discovery of patterns in the data and identification of any commonalities and differences among the categories. ${ }^{42}$ This process led to the broad categories being refined into themes based on the connection of patterns in the data and from the concepts that frequently occurred across categories and sessions. Although the data within and across categories were reviewed to construct social support themes based broadly on the social support literature, the analysis also allowed for emergent themes.

An iterative process in the data analysis was used in which data were coded and recoded to accommodate new emerging themes until no new themes emerged $^{33,42}$ and 2 final group interviews (one male and one female) confirmed previously emerging themes and ensured that theoretical saturation had been attained. ${ }^{42}$ To ensure quality control in the data, confirming summaries occurred throughout the interview discussions (credibility), a community sample was used (transferability), and disinterested peers participated in data reduction (ie, 2 individuals with university health-related degree qualifications reviewed sections of deidentified transcripts and commented on emerging themes as being an accurate reflection of the views of the participants) (confirmability). ${ }^{39}$ In addition, the reflective journal kept by the interviewer helped facilitate the data interpretation process as well as helped to ensure that identified categories fitted the data. ${ }^{39}$

\section{RESULTS}

The parents' descriptions provide an understanding of how supportive social environments affect parental PA-related behavior. The results were consistent across the individual and group interviews and, therefore, the most salient emerging themes expressed across all participants are presented. Overall, 5 social support dimensions were identified from the data. Refer to Table 2 for a summary of the social support types, sources, major themes, and selected quotes for mothers and fathers.

\section{Instrumental Support}

Both mothers and fathers reported that their partners provided the most important source of instrumental support; although other family members, community organizations, friends, and neighbors were also identified as sources of instrumental support. Specifically, physical tangible assistance emerged as the most salient form of instrumental support facilitating activity performance. In particular, assistance with household chores and child care, either present or absent, affected parents' PA. In analyzing any differences across the parent groups, however, it was noted that the majority of mothers, compared to only some of the fathers, reported this type of assistance as important. One father explained, "As far as I feel, I'm getting enough exercise commuting to and from work on my bike. I don't need to call on the support of others to get myself into an active situation." These fathers described how they had opportunities to be active that did not involve the need for child care, such as being active at work or travelling to work.

A theme of family alleviates guilt also emerged from the data in which family members were described as a source of instrumental support that allows one to engage in PA free of any guilt. This freedom of guilt was a result of parents' perceiving that their children would not be exposed to any undue stress from being cared for by an unknown caregiver (eg, care from individuals in community settings) as well as from perceiving that their children would be spending quality time with a parent/relative. Furthermore, in reviewing parents' descriptions of this notion of family members' relieving guilt 
for being active, it was noted that this perception was both speculative in nature in that parents described that family taking care of the children would lessen their guilt for engaging in PA and nonspeculative in that family members actually alleviated guilt for one's activity habits. As one father described, "She's [wife] great with the kids ... and if she wasn't so great with the kids I'd have no hope at all of going out for a run. . . I don't have to worry or get the guilts about the kids because I know she's with them. . . . So, that's important."

Having tangible assistance for activity performance, however, is not that simple. In discussions with parents about support for child care emerged the theme of guilt in getting help. This guilt, in particular, stemmed from perceiving that they have to ask others for the help, that others will be burdened if they are required to care for their children, and from a feeling that they will be dumping or offloading their children onto someone else for their own activity purposes. Additionally, for a few mothers, a further theme of resentment in asking for help emerged in which these mothers resented the fact that they had to ask their partners for help rather than receiving unprompted assistance: "You know, if I asked or said to him I need you to look after Sammy for an hour 3 days a week so I can go exercise, he'd go yeah no worries. But I resent having to ask." [Mother].

\section{Emotional Support}

Emotional support in the form of encouragement and companionship given by partners and friends (but also to some extent given by other family members, mothers' group, neighbors, and work colleagues) was reported as a salient influence for both mothers' and fathers' PA behavior. These particular sources of support were described as providing the necessary encouragement to help one be regularly active. These particular individuals were described also as giving companionship in which activities performed with others was considered helpful in motivating activity performance. However, in discussions of encouragement support a few parents perceived that the support only added to their guilt of being inactive. As one father described, "Yes I do have that encouragement, but it's not a big motivator. It probably just adds to the guilt at the end of the day."

An inherent paradox in parents' beliefs surrounding emotional support was the theme in/activity criticism in which a few parents perceived that the criticism from family members and friends toward not being active was motivating: "Both, well my family didn't call me a fat bastard they did think it though, but yeah my friends did. . . . And it was motivating for me to actually get me off my backside and do something about it." [Father]. Other parents, however, felt the criticism they received for being inactive was demotivating: "They [active friends] look upon me as being a lazy slob . . . it can often make me feel quite uncomfortable rather than work the other way round." [Mother]. Furthermore, a few parents described how they received criticism for being active, which, in turn, reduced their activity levels. As one father explained, "I can be criticized at home for doing too much physical activity . . . sometimes it can work against me . . . so I tend to do less to keep the peace."

\section{Informational Support}

Overall, although family members, doctors, and health organizations were identified as sources of informational support, friends were reported by the majority of parents as providing this type of support. Friends were described as giving advice and good ideas on ways to be active highlighted by the theme ideas and advice. Parents often described that their friends provided them with ideas regarding new and alternative ways of being active as well as advice on opportunities that existed that might help one to be active. Despite this type of informational support, however, the majority of parents believed they had sufficient knowledge about PA, and for some parents, the theme information overload emerged, in which the information from health authorities promoting being active was perceived as only adding to their pressures.

\section{Reciprocal Support}

The notion of reciprocal support also emerged from the data; specifically, child care and encouragement were the types of reciprocal support identified. Both mothers and fathers described how they supported their partners and friends in their activity endeavours as well as how the support was returned for their own activ- 
ity purposes. One mother explained, "You know what it's like talking to other mothers, it's all that struggle of get this done, get that done and it feels really good to help someone else out and get the help yourself so we can all get to do a bit of physical exercise."

However, in some of the mothers' discussions on reciprocal support emerged the themes additional pressure and need for confidence in which some mothers felt that having a reciprocal agreement would only add additional pressure to their already overwhelming lives and that one would need the confidence to look after other people's children. In addition, a few mothers perceived that in their busy lives there was only opportunity to provide oneway support, highlighted in the theme support partner but no opportunity for reciprocity. As one mother explained, "Just being that set with the system cause my husband plays organized sport and I support that, but something had to give somewhere. . . I It's just not an option for both of us to be doing it."

\section{Autonomy Support}

Emerging from mothers' discussions on supportive social environments were 3 strong themes: need for own choice and perspective, need for understanding, and wanting to be treated differently. These themes encompass the higher order social support dimension of autonomy support in which mothers described that they now had specific needs for activity performance that were not present before having children. In particular, these mothers felt that they wanted to make their own choices on activity performance, have an understanding from others for their need to be active, and be treated differently because of their additional needs as a result of being mother. These findings highlight that the quality of social contexts that emphasize the minimization of controls and promote choices ${ }^{\text {see }} 43$ are particularly salient for mothers of young children.

\section{DISCUSSION}

Drawing from social support theories $^{14,16,17}$ that emphasize the different sources, types, and directions of support as affecting health behavior, this study illustrates how parents perceive supportive social environments as influencing their PA. In this study, instrumental sup- port (eg, child care, housekeeping), emotional support (eg, encouragement/criticism, companionship), and informational support (eg, ideas, advice), either present or absent, from partners, family members, friends, neighbors, work colleagues, and community members were important influences on parental PA. These findings, however, are not entirely straightforward. Although the study's results highlight the importance of different types and sources of support in facilitating activity performance, which is consistent with previous research, the findings do not fit exactly current conceptualizations of social support. First, a guilt complex often influenced parents' perceptions of instrumental support in which both mothers and fathers described that assistance with child care, in particular, needed to be sourced from either partners or family members as they alleviated any feelings of guilt for being active. Despite having support available, however, many parents felt guilty in asking for the help to be active, and a few mothers described resenting the need to ask. Second, although emotional support can help facilitate motivation for activity performance, encouragement can also add to one's guilt for being inactive. Additionally, criticism from others, although described as a demotivator, was also shown to be a motivator for doing something about the lack of activity being performed. Third, parents perceived that informational support was a good way of obtaining new ideas for being active, but it was also perceived as overwhelming and only adding to the pressures already experienced by being a parent.

By examining the data of both mothers' and fathers' perceptions of social support for PA, some differences between the sexes were identified. Specifically, although the majority of mothers reported that social support for activity performance is important, which is consistent with previous research, ${ }^{44,45}$ some of the fathers perceived that having PA support was not necessary. This finding is consistent with research suggesting that females, rather than males, are affected more by having support for activity performance. ${ }^{23,24}$ Furthermore, the finding suggests that fathers may have more opportunities to be active independently and that the prevailing ethic of care ${ }^{6}$ in which it is difficult to priorities one's own needs over the 


\section{Table 2}

\section{Summary of Social Support Findings: Types, Sources, Major Themes, and Selected Quotes for Mothers and Fathers}

\begin{tabular}{ll}
\hline Types & Sources \\
\hline Instru- & Partner ${ }^{\mathrm{a}}$ \\
mental & Other family members \\
Support & Friends \\
& Neighbors \\
& Community
\end{tabular}

Emotional Partner ${ }^{\mathrm{a}}$ Support Friends ${ }^{\mathrm{a}}$

Other family members Mothers' group Work colleagues Neighbors

Informa-

tional

Support

Family members

Doctors

\author{
Major Themes and Selected Quotes
}

Physical tangible assistance: access to child care; taking over chores

"He'll [husband] start work late and look after the kids, do a little housework, so I can have my morning [exercise] session." [Mother] Family alleviates guilt

"Well I guess probably if the assistance was my husband or my mum looking after the children I wouldn't feel as guilty because at least I'd know they'd be spending some quality time with a parent or a relative." [Mother]

"If it's a family member . . . the kids would find enjoyment in that . . . you're not having to say, 'right suck it up' or whatever because they're upset at some stranger looking after them." [Father]

Guilt in getting help: asking for help

"I'm sure he'd [husband] love to do it, it's just I feel guilty in asking him to mind Billy." [Mother]

"I'd feel a little guilty in asking her [wife] to mind the kids when she's looked after them all day just so I could go off for a bike ride sort of thing." [Father]

Guilt in getting help: burdening others

"You think, well I've got 2 [children] what's another bring them round I've got a DVD. But then again it comes back to that I wouldn't want to burden another mother with my kids while I go have a good time at the gym you know." [Mother]

"The child minding would be the big one, but obviously there's only so much you can ask parents or family to do because they're got their lives as well." [Father]

\section{Guilt in getting help: offloading the children}

"I don't know if I suffer a guilt complex or not, but I don't feel I could dump the kids in child minding and go off and do sport." [Mother]

"But I think if you were to dump them in day care or whatever so you could do physical activity my belief is that's not much of a parent." [Father]

\section{Encouragement}

"My husband does try to encourage me and does say when I get home from work you know go for a walk." [Mother]

"If anything my wife actually encourages me to do it. She's very supportive of me in the exercise area. And that really helps to keep me motivated to keep on doing it." [Father]

\section{Companionship}

"But I do it with a friend of mine and that's a big motivator." [Father] "And I think exercise is more fun when you can do it regularly with other people because that does tend to keep you motivated" [Mother]

\section{Ideas and advice}

Health organizations
"I guess some of the mums from playgroup . . . like everyone's very supportive of like passing on ideas that you never thought about before." [Mother]

"Yeah well the people I work with, my work mates, there's a few in particular who are great in getting ideas from. They're always coming up with great ways to get out and do stuff." [Father]

\section{Information overload}

"Information not so much, like I get the active part and we do do some of them, but more often it feels like the 'must-ist', I must do this, I must do this and I must do this. . . So sometimes the information is good, but it does just feel like information overload." [Mother] 
Table 2 (continued)

Summary of Social Support Findings: Types, Sources, Major Themes, and Selected Quotes for Mothers and Fathers

\begin{tabular}{ll} 
Types & Sources \\
\hline Reciprocal & Friends \\
Support & Partner $^{\mathrm{a}}$
\end{tabular}

Autonomy Partner ${ }^{\mathrm{a}}$

Support Other family members Community
Major Themes and Selected Quotes

\section{Encouragement}

"We have tried to engineer our time to get ourselves up off the couch when you tend to flop down sort of at the end of each day and find some little bit of motivation between us as a couple and encourage each other to exercise." [Father]

Child care

"We go swimming in that one of us can swim and the other one keeps an eye on the kids, because you know I can't go with the 2 girls and swim. ..." [Mother] Additional pressure ${ }^{\mathrm{b}}$

"I find looking after 2 kids and running a household is more stressful than I've found anything else I've done. . . . . Having an agreement with another mum where I look after their kids and they look after mine so we can do exercise would feel a bit like having a binding contract. And I don't need that extra pressure at the moment." [Mother]

Need for confidence ${ }^{\mathrm{b}}$

"I'd need to feel comfortable about looking after another child. . . . I think I'd feel more comfortable looking after a girl baby cause I have a girl baby, but looking after a boy baby I'd be like oh god I've never changed a boy's nappy, which is so stupid." [Mother]

\section{Need for own choice and perspective ${ }^{\mathrm{b}}$}

"If I was to go for a walk this evening . . . I'd say I've gone for a walk purely for the fact that it's a nice night and I wanted to do it, not if I was given a schedule to do it and someone told me to do it." [Mother] Need for understanding ${ }^{\mathrm{b}}$

"I wish that my husband understood what it feels like to be at home with the baby. Like I think women feel so much better when they're active, men do too, but I don't think my husband really understands. I wish he would make more of an effort to take time off my hands so I could do more exercise." [Mother]

Wanting to be treated differently ${ }^{\mathrm{b}}$

"I guess that's with the gym ... I didn't feel I'd be treated differently. Where now, being a mum, I feel I need a different sort of encouragement. And I don't know maybe that's me." [Mother]

Note:

a Represents the most salient source of support for the corresponding type of support

b Represents themes from the voices of mothers

needs of the family, is more prevalent for mothers. The results of this study also show that, although both mothers and fathers perceive child care and encouragement as a reciprocal process that facilitates activity performance, mothers further perceive difficulties associated with such support. In particular, mothers described the additional pressure it creates, the need for confidence to care for others' children, and the lack of opportunity for reciprocity (ie, they supported their partners' activity, but there was no opportunity for their partner to reciprocate the support). These complexities associated with reciprocal support for mothers might help to explain why females' activity levels, rather than males' activity levels, decline more with the presence of children. ${ }^{5}$ Finally, the data revealed that mothers have a desire to assert authority over their PA behavior in which some of the mothers discussed how they want others to support their autonomy for being active and the data suggested that nonpressuring forms of 
social influence are particularly salient for mothers of young children. This finding is consistent with research suggesting that autonomy support, which emphasizes the provision of choices and understanding of one's own perspective, ${ }^{43}$ facilitates activity performance ${ }^{43,46,47}$ and highlights further why females, rather than males, perceive social support as important for their PA-related behavior.

Although much research has been conducted into the effects of social support on activity performance, research using qualitative methodologies within defined population groups is scarce. ${ }^{48}$ We believe, therefore, that our findings contribute to the extant literature in a number of important ways. First, the study fills an empirical gap in relation to parental PA in which both mothers' and fathers' perceptions of supportive environments were investigated. Examining the influences on both sexes and explicitly comparing the similarities and differences is important given that both females ${ }^{29,30}$ and males'31 PA decline with the presence of children. Second, the study gained a rich understanding beyond survey methodology of the interrelationships among the supportive dimensions. Although this study's findings had some consistency with the social support literature employing quantitative methodologies (ie, identification of the different sources and types of support), by using qualitative methods, we identified some caveats to current social support classifications. For example, although parents perceive social support for PA as important, guilt issues may influence taking advantage of these supportive networks. Third, as parents described many types of support as facilitating their activity performance and this support as coming from a range of different people in their lives, our work illustrates that adopting theoretical approaches that advocate multidimensional constructs of social supporteg,14 is important when trying to understand parental PA.

Our study has some limitations. First, the research focused on understanding PA from the perspective of the individual and, therefore, did not capitalize on natural interactions that occur across generations. The family represents one such naturally occurring multigenerational unit. However, although targeting the family in understanding PA seems oppor- tune, research suggests that targeting the individual is beneficial in understanding PA behavior. ${ }^{49}$ Second, the target population chosen (ie, parents of young children) may not be representative of the entire parental population. Although research suggests that PA declines are most prominent in parents with younger children, ${ }^{5}$ the current findings might not fit with parents of older children. Future research, then, is needed to confirm these findings and expand on the identified themes across family lifecycles. Additionally, the study participants were white, and much research within the PA domain has highlighted the importance of cultural beliefs about PA; ; ${ }^{50,51}$ thus, the findings may not generalize to parents of various ethnic groups. The snowball recruitment method might have also resulted in a sample bias as participants may have perceptions similar to those of the individuals recruiting them. ${ }^{52}$ For example, the relatively high number of mothers with university degree qualifications might have biased the data in that they may be more informed about and have more access to various forms of support. As such, other salient issues surrounding social support for activity performance for this target population might not have emerged from the data. Finally, the interview guide used openended questions; however, the topics were informed by social support theories that may have limited the study's scope. For example, social support theories do not tap into guilt-related issues, and given that guilt-related themes emerged from the data, further investigation of the effect of guilt on parents' PA seems warranted. Future research, then, should continue to explore how guilt in relation to social support may be minimized in relation to people's level of PA or whether these themes are the result of a rationalization process to maintain an inactive lifestyle.

Despite the study's limitations, our findings have important practical implications for intervention programs aimed at increasing parental PA. Although the importance of social support for PA performance has been widely accepted, ${ }^{10}$ our findings highlight the complexity of supportive environments in facilitating parental PA. Thus, although it may be advantageous to promote supportive environments, these messages need to be 
couched with appropriate messages that alleviate guilt and promote an acceptance for receiving the help from others to be active. One possibility is to promote the benefits of activity performance on parenting practices as well as the benefits to the child of spending time with others. Additionally, messages could promote the importance of offering help. Furthermore, health authorities may need to rethink informational campaigns promoting being active and reframe messages in a way that they do not add to the pressures already felt by parents and, for mothers in particular, promote a sense of autonomy over their activity behavior. For example, messages encouraging active lifestyles should place more focus on household (eg, performing housework more vigorously) and occupational (eg, using stairs) physical activities with an emphasis on these activities as not necessarily creating any extra pressure to everyday living. Additionally, messages could give more focus on promoting choices for activity performance, such as promoting the acceptance of unstructured (eg, playing active games with the children) as well as structured activities, and provide advice and opportunities (eg, access to integrative child/parent programs or facilities that have flexible child care) that will help parents be active in the ways that they wish. Finally, our findings help remind us that reciprocal support is important to consider but that campaigns may need to concentrate on promoting the opportunities and confidence in requesting and acting on this type of support.

Effective promotion of PA in parents of young children is essential given the low rate of activity in this population. This study highlights the complex nature of social support in facilitating parental PA, but provides also a foundation on which to build effective interventions targeting supportive social environments aimed at increasing parental PA.

\section{REFERNCES}

1.Begg S, Vos T, Baker B, et al. The Burden of Disease and Injury in Australia 2003. Canberra: AIHW 2007.

2.Australian Government Department of Health and Aging. an Active Way to Better Health: National Physical Activity Guidelines. Canberra: Commonwealth of Australia 2005.

3.Australian Bureau of Statistics 2004-05. Physical Activity in Australia: A Snapshot. Canberra:
ABS 2006.

4.Bellows-Riecken KH, Rhodes RE. A birth of inactivity? A review of physical activity and parenthood. Prev Med. 2008;46:99-110.

5.Nomaguchi KM, Bianchi S M. Exercise time: gender differences in the effects of marriage, parenthood, and employment. J Marriage Fam. 2004;66:413-430.

6.Lewis B, Ridge D. Mothers reframing physical activity: family oriented politicism, transgression and contested expertise in Australia. Soc Sci Med. 2005;60:2295-2306.

7.Pugliese J, Tinsley B. Parental socialization of child and adolescent physical activity: a metaanalysis. J Fam Psychol. 2007;21:331-343.

8. Mattocks C, Deere K, Leary S, et al. Early life determinants of physical activity in 11 to 12 year olds: cohort study. BMJ. 2008;336:2629.

9.Anshel M. Conceptualizing applied exercise psychology. J Am Board Sport Psychol. 2007;1:144.

10.Sallis JF, Owen N. Physical Activity \& Behavioral Medicine. Thousand Oaks: Sage Publications 1999.

11. Courneya KS, Plotnikoff RC, Hotz SB, Birkett NJ. Social support and the theory of planned behavior in the exercise domain. Am J Health Behav. 2000;24:300-308.

12. Lewis BA, Marcus BH, Pate RR, Dunn AL. Psychosocial mediators of physical activity behavior among adults and children. Am J Prev Med. 2002;23:26-35.

13. Heaney CA, Israel BA. Social networks and social support. In: Health Behavior and Health Education. Edited by Glanz K, Rimer BK, Lewis FM. San Francisco: Jossey-Bass 2002:185-209.

14.House JS. Work Stress and Social Support. Reading: Addison-Wesley 1981.

15.Antonucci TC. Personal characteristics, social networks, and social behavior. In: Handbook of Aging and the Social Sciences. Edited by Binstock RH, Shanas E. New York: Van Nostrand Reinhold 1985:94-128.

16. Cutrona CE, Russell DW. The provisions of social relationships and adaptation to stress. In: Advances in Personal Relationships. Edited by Jones WH, Perlman D. Greenwich: JAI Press 1987:37-67.

17.Sallis JF, Grossman RM, Pinski RB, et al. The development of scales to measure social support for diet and exercise behaviors. Prev Med. 1987; 16:825-836.

18. Cohen S, Syme SL. Issues in the study and application of social support. In: Social Support and Health. Edited by Cohen S, Syme SL. Orlando: Academic Press 1985:3-22.

19.Hupcey JE. Clarifying the social support theory-research linkage. $J A d v$ Nurs. 1998;27:1231-1241.

20. Hamilton K, White KM. Extending the theory of planned behavior: the role of self and social influences in predicting adolescent regular moderate-to-vigorous physical activity. J Sport 
Exerc Psychol. 2008;30:56-74.

21.Sharma M, Sargent L, Stacy R. Predictors of leisure-time physical activity among African American women. Am J Health Behav. 2005;29:352-359.

22. Thornton PL, Kieffer EC, Salabarría-Peña Y, et al. Weight, diet, and physical activityrelated beliefs and practices among pregnant and postpartum Latino woman: the role of social support. Matern Child Health J. 2006;10:95-104.

23. Leslie E, Owen N, Salmon J, et al. Insufficiently active Australian college students: perceived personal, social, and environmental influences. Prev Med. 1999;28:20-27.

24.Phongsavan P, McLean G, Bauman A. Gender differences in influences of perceived environmental and psychosocial correlates on recommended level of physical activity among New Zealanders. Psychol Sport Excer. 2007;8:939-950.

25. Marshall C, Rossman GB. Designing Qualitative Research. Thousand Oaks: Sage Publications 2006.

26.Bialeschki MD, Michener S. Re-entering leisure: transition within the role of motherhood. J Leisure Res. 1994;26:57-74.

27.Jenkins C, Handcock P, Burrows L, Hodge K. Exercise barriers faced by first-time mothers. New Zeal College Midwives J. 2006;35:6-11.

28.Kay T. Having it all or doing it all? The construction of woman's lifestyles in timecrunched households. Soc Leisure. 1998;2 1:435-454.

29.Bell S, Lee C. Emerging adulthood and patterns of physical activity among young Australian woman. Int J Behav Med. 2005;12:227235.

30.McIntyre CA, Rhodes RE. Correlates of leisure-time physical activity during transitions to motherhood. Woman Health. 2009;49:6683.

31.Burton NW, Turrell G. Occupation, hours worked, and leisure-time physical activity. Prev Med. 2000;31:673-681.

32. Patton MQ. Qualitative Research and Evaluation Methods. Thousand Oaks: Sage Publications 2002.

33. Strauss A. Qualitative Analysis for Social Scientists. Cambridge: Cambridge University Press 1987.

34. Sandelowski M. Whatever happened to qualitative description? Res Nurs Health. 2000;23:334-340.

35. Krueger RA, Casey MA. Focus Groups. A Practical Guide for Applied Research. Thousand Oaks: Sage Publications 2000.

36. Morgan DL. Focus Groups as Qualitative Re- search. Thousand Oaks: Sage Publications 1998.

37.Krueger RA. Developing Questions for Focus Groups. Thousand Oaks: Sage Publications 1998.

38.Ahern KJ. Ten tips for reflexive bracketing. Qual Health Res. 1999;9:407-411.

39.Lincoln YS, Guba EG. Naturalistic Inquiry. Beverly Hills: Sage Publications 1985.

40.Braun V, Clarke V. Using thematic analysis in psychology. Qual Res Psychol. 2006;3:77101 .

41.Joffe H, Yardley L. Content and thematic analysis. In: Research Methods for Clinical and Health Psychology. Edited by Marks DF, Yardley L. London: Sage Publications 2004:5668.

42. Miles MB, Huberman AM. Qualitative Data Analysis. London: Sage Publications 1994.

43.Deci EL, Ryan RM. Facilitating optimal motivation and psychological well-being across life's domains. Can Psychol. 2008;49:14-23.

44.Brown PR, Brown WJ, Miller YD, Hansen V. Perceived constraints and social support for active leisure among mothers with young children. Leisure Sci. 2001;23:131-144.

45.Cleland VJ, Timperio A, Crawford D. Are perceptions of the physical and social environment associated with mothers' walking for leisure and for transport? A longitudinal study. Prev Med. 2008;47:188-193.

46. Chatzisarantis NLD, Hagger MS, Brett S. Influences of perceived autonomy support on physical activity within the theory of planned behavior. Europ J Social Psychol. 2007;37:934-954.

47.Wilson PM, Rodgers WM. The relationship between perceived autonomy support, exercise regulations and behavioral intentions in women. Psychol Sport Exerc. 2004;5:229-242.

48. Allender S, Cowburn G, Foster C. Understanding participation in sport and physical activity among children and adults: a review of qualitative studies. Health Educ Res. 2006;21:826-835.

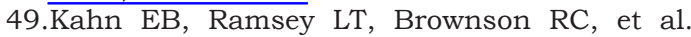
The effectiveness of interventions to increase physical activity: a systematic review. Am J Prev Med. 2002;22: S73-S107.

50.Fahrenwald NL, Shangreaux P. Physical activity behavior of American Indian mothers. Orthop Nurs. 2006;25:22-29.

51. Fleury J, Lee SM. The social ecological model and physical activity in African American women. Am J Commun Psychol. 2006;37:129140 .

52.Brace-Govan J. Issues in snowball sampling: the lawyer, the model and ethics. Qual Res $J$. 2004;4:52-60. 